\title{
Commentary: What makes the morphologically left ventricle double chambered?
}

\author{
Robert H. Anderson, BSc, MD, FRCPath, PhD Hon, FRCS Ed Hon, ${ }^{a}$ and Hubert Gufler, MD
}

\author{
${ }^{\mathrm{a}}$ From the Institute of Genetic Medicine, Newcastle University, Newcastle-upon-Tyne, United Kingdom; and the \\ ${ }^{\mathrm{b}}$ Clinic and Policlinic of Radiology, Martin Luther University Halle-Wittenberg, Halle (Saale) Germany. \\ Disclosures: Authors have nothing to disclose with regard to commercial support. \\ Received for publication July 1, 2019; accepted for publication July 1, 2019; available ahead of print Aug 9, 2019 \\ Address for reprints: Robert H. Anderson, BSc, MD, FRCPath, PhD Hon, FRCS Ed Hon, 60 Earlsfield Rd, Lon- \\ don SW18 3DN, United Kingdom (E-mail: sejjran@ucl.ac.uk) \\ J Thorac Cardiovasc Surg 2020;159:e195-6 \\ 0022-5223/\$36.00 \\ Copyright (C) 2019 by The American Association for Thoracic Surgery \\ https://doi.org/10.1016/j.jtcvs.2019.07.012
}

As is indicated by Park and colleagues ${ }^{1}$ in their discussion in this issue of the Journal of the potential for congenital division of the morphologically left ventricle, this entity is appreciably rarer than comparable congenital division of the morphologically right ventricle. The use of search engines such as Google, nonetheless, now shows that the lesion is being encountered and described with increasing frequency, albeit usually as individual case reports. The largest series of lesions has been described subsequent to examination of an archive of autopsied hearts, including division of both the right and left ventricles. ${ }^{2}$ As Park and colleagues ${ }^{1}$ emphasize, the congenitally divided right ventricle can itself appear in several guises. Many consider the entity to be produced by a prominent anomalous trabeculation spanning the ventricular cavity. Such an anomalous trabeculation, however, does not obviously divide the ventricle into 2 components. A double-chambered arrangement is much more readily recognized when a prominent myocardial shelf, itself formed by condensed trabeculations, divides the apical component into obvious inlet and outlet parts. ${ }^{3}$ It is much harder to provide an explanation for the congenital malformations that might produce a comparable 2-chambered arrangement within the morphologically left ventricle. This is in part because the apical trabeculations of the morphologically left ventricle are fine and crisscross, in contrast to the coarse trabeculations found at the apex of the right ventricle. And septoparietal trabeculations, spanning from the septal to the parietal walls, are found only within the morphologically right ventricle. As already indicated, nonetheless, reports are beginning to appear with increasing frequency of division of the left ventricle, perhaps because of the increasing use of 3-dimensional techniques during cardiac diagnosis. $^{4-6}$

The current case showing congenital division of the morphologically left ventricle is further complicated, because Park and colleagues ${ }^{1}$ suggest that their patient also had an ischemic aneurysm develop, thus potentially producing the arrangement in which the left ventricle

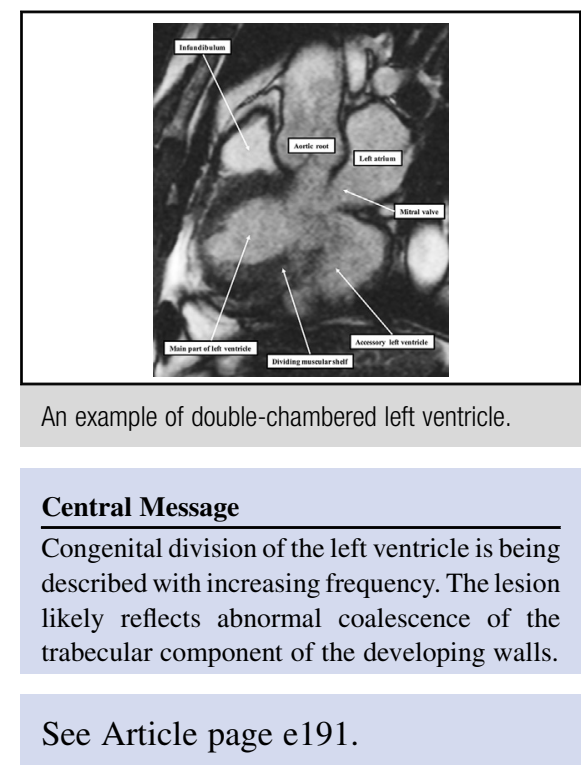

possessed 3, rather than 2, components. They suggest that the aneurysm itself ballooned from both of the divided components. We confess that we find it exceedingly difficult to correlate the images obtained in the operating room with those produced by their 3-dimensional reconstruction. To our eyes, the alleged dividing shelf could just as easily be interpreted as representing the parietal wall of the left ventricle, with the purported second ventricular component itself being the aneurysm, because it seems that only the chamber labelled as "LV2" possesses apical trabeculations. This could be significant, because in one of the earliest accounts of a series of patients with congenital division of the left ventricle, Gerlis and associates ${ }^{7}$ suggested that a similar arrangement was indeed due to division of the parietal ventricular wall. In the series reported by Gerlis and associates, ${ }^{7}$ the other 2 cases showed evidence of sequestration of the entirety of the apical component of the left ventricle from its inlet and outlet components. In collaboration with Anton Becker, in our textbook Cardiac Pathology, one of us (R.H.A.) published a case with sequestration of the apical component of the right ventricle. ${ }^{8}$ In retrospect, it is clear that the heart in question came from a patient with excessive apical trabeculations, the arrangement frequently described as noncompaction, and that the apical part of the left ventricle is similarly sequestrated. We recently encountered another case in which the dividing shelf in the left ventricle was likely the consequence of abnormal coalescence of the trabecular component of the developing ventricular wall 


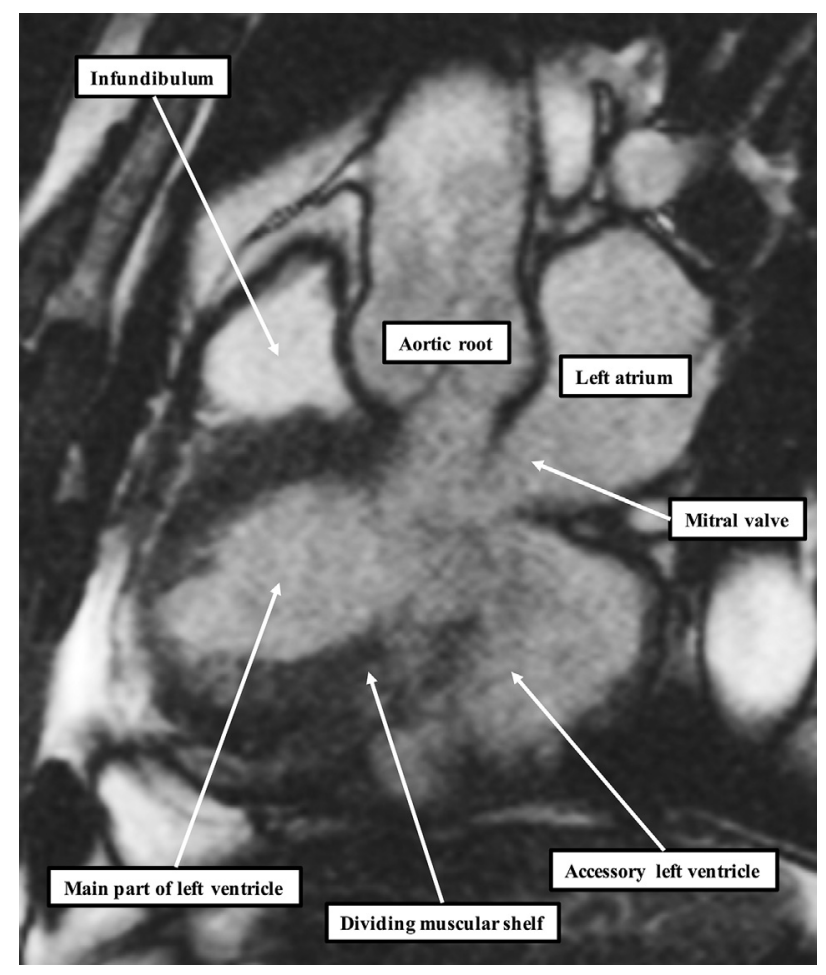

FIGURE 1. An example of double-chambered left ventricle.

(Figure 1). ${ }^{6}$ Although there is no evidence to show that such initial trabeculations during development form the normal compact component of the wall, they almost certainly do coalesce to produce the papillary muscles in both ventricles. In this regard, in the majority of the cases described thus far, the dividing myocardial shelf within the left ventricle has been closely related with the papillary muscles of the mitral valve (Figure 1). It seems likely, therefore, that in both variants of double-chambered ventricles, it is the manner of coalescence of the trabecular component of the developing ventricular walls that underscores the morphogenesis. The good news is that, irrespective of the interpretation of the findings, the surgical outcome in the case reported by Park and colleagues ${ }^{1}$ was excellent.

\section{References}

1. Park WK, Kim DH, Kwak YT, Cho SH. Double-chambered left ventricle discovered in patient with ruptured left ventricular aneurysm after myocardial infarction. J Thorac Cardiovasc Surg. 2020;159:e191-4.

2. Kumar GR, Vaideswar P, Agrawal N, Khandeparkar J, Khandekar J, Patwardhan A. Double chambered ventricles: a retrospective clinicopathological study. Ind J Thorac Cardiovasc Surg. 2007;23:135-40.

3. Restivo A, Cameron AH, Anderson RH, Allwork SP. Divided right ventricle: a review of its anatomical varieties. Pediatr Cardiol. 1984;5:197-204.

4. Partington SL, Ali B, Daly RP, Koplan BA, Lilly LS, Solomon SD, et al. Images in cardiovascular medicine. Initial presentation of an accessory left ventricle in a patient with syncope. Circulation. 2010;121:e401-3.

5. Masci PG, Pucci A, Fontanive P, Coceani M, Marraccini P, Lombardi M. Double chambered left ventricle in an asymptomatic adult patient. Eur Heart J Cardiovasc Imaging. 2012;13:E1-3.

6. Gufler H, Anderson RH, Annette M, Voigtlaender T. Double-chambered left ventricle in a patient with chest pain. Clin Res Cardiol. 2018;107:1180-2.

7. Gerlis LM, Partridge JB, Fiddler GI, William G, Scott O. Two chambered left ventricle. Three new varieties. Br Heart J. 1981;46:278-84.

8. Becker A, Anderson RH. Cardiac Pathology: An Integrated Text and Colour Atlas. London: Churchill Livingstone; 1984. 12.10. 